\title{
Common fixed point for mappings satisfying new contractive condition and applications to integral equations
}

\author{
Feng $\mathrm{Gu}^{\mathrm{a}, *}$, Hongqing $\mathrm{Ye}^{\mathrm{b}}$ \\ a Institute of Applied Mathematics and Department of Mathematics, Hangzhou Normal University, Hangzhou, Zhejiang 310036, China. \\ ${ }^{b}$ Hangzhou Wenchang High School, Hangzhou, Zhejiang 311121, China.
}

Communicated by Y. J. Cho

\begin{abstract}
In this paper, we prove some common fixed point theorems for three self-mappings satisfying various new contractive conditions in complete G-metric spaces. We also discuss that these mappings are G-continuous on such a common fixed point. And a non-trivial example is provided to support our new result in the framework of nonsymmetric G-metric spaces. At the end of the results, we give an existence theorem for common solution of three integral equations. The results obtained in this paper differ from the recent relative results in literature. (C)2017 All rights reserved.
\end{abstract}

Keywords: Common fixed point, generalized metric space, integral equation. 2010 MSC: 47H10, 54H25.

\section{Introduction and preliminaries}

The study of fixed points of mappings satisfying certain contractive conditions has been in the center of rigorous research activity. In 2006, a new structure of generalized metric space was introduced by Mustafa and Sims [12] as an appropriate notion of generalized metric space called G-metric space. Abbas and Rhoades [2] initiated the study of common fixed point in generalized metric space. Recently, many fixed point theorems for certain contractive conditions have been established in G-metric spaces, and for more details one can refer to [1-17]. Recently, Gu and Zhang [7] proved a common fixed point theorems for six self-mappings with twice power type contractive condition in metric space. In 2002, Gu et al. [4] proved a common fixed point theorem for four self-mappings with third power type contractive condition in metric space. In 2012, Ye and Gu [17] proved a common fixed point theorems for four self-mappings with four power type contractive condition in metric space.

Motivated by the recent works, in this paper, we introduce some new contraction condition on Gmetric space for three self-mappings, and we prove some new common fixed point theorems. The results obtained in this paper differ from the recent relative results in literature.

Throughout the paper, we mean by $\mathbb{N}$ the set of all natural numbers. Consistent with Mustafa and Sims [12], the following definitions and results will be needed in the sequel.

\footnotetext{
*Corresponding author

Email addresses: mathguf eng@163.com (Feng Gu), weili5412783137@qq.com (Hongqing Ye)
} 
Definition 1.1 ([12]). Let $X$ be a nonempty set, and let $G: X \times X \times X \longrightarrow R^{+}$be a function satisfying the following axioms:

(G1) $G(x, y, z)=0$ if $x=y=z$;

(G2) $0<G(x, x, y)$ for all $x, y \in X$ with $x \neq y$;

(G3) $G(x, x, y) \leqslant G(x, y, z)$ for all $x, y, z \in X$ with $z \neq y$;

(G4) $\mathrm{G}(x, y, z)=\mathrm{G}(x, z, y)=\mathrm{G}(y, z, x)=\cdots$ (symmetry in all three variables);

(G5) $G(x, y, z) \leqslant G(x, a, a)+G(a, y, z)$ for all $x, y, z, a \in X$ (rectangle inequality);

then the function $G$ is called a generalized metric, or, more specifically a $G$-metric on $X$ and the pair $(X, G)$ is called a G-metric space.

Definition 1.2 ([12]). Let (X, G) be a G-metric space, and let $\left\{x_{n}\right\}$ be a sequence of points in $X$, a point $x$ in $X$ is said to be the limit of the sequence $\left\{x_{n}\right\}$ if $\lim _{m, n \rightarrow \infty} G\left(x, x_{n}, x_{m}\right)=0$, and one says that sequence $\left\{x_{n}\right\}$ is G-convergent to $x$. Thus, if $x_{n} \rightarrow x$ in a G-metric space $(X, G)$, then for any $\epsilon>0$, there exists $N \in \mathbb{N}$ such that $G\left(x, x_{n}, x_{m}\right)<\epsilon$ for all $n, m \geqslant N$.

Proposition 1.3 ([12]). Let (X, G) be a G-metric space, then the following are equivalent.

(1) $\left\{x_{n}\right\}$ is G-convergent to $x$.

(2) $\mathrm{G}\left(\mathrm{x}_{\mathrm{n}}, \mathrm{x}_{\mathrm{n}}, \mathrm{x}\right) \rightarrow 0$ as $\mathrm{n} \rightarrow \infty$.

(3) $\mathrm{G}\left(\mathrm{x}_{\mathrm{n}}, \mathrm{x}, \mathrm{x}\right) \rightarrow 0$ as $\mathrm{n} \rightarrow \infty$.

(4) $\mathrm{G}\left(\mathrm{x}_{\mathrm{n}}, \mathrm{x}_{\mathrm{m}}, \mathrm{x}\right) \rightarrow 0$ as $\mathrm{n}, \mathrm{m} \rightarrow \infty$.

Definition $1.4([12])$. Let $(X, G)$ be a G-metric space. A sequence $\left\{x_{n}\right\}$ is called G-Cauchy sequence if for each $\epsilon>0$ there exists a positive integer $N \in \mathbb{N}$ such that $G\left(x_{n}, x_{m}, x_{l}\right)<\epsilon$ for all $n, m, l \geqslant N$; that is $\mathrm{G}\left(\mathrm{x}_{\mathrm{n}}, \mathrm{x}_{\mathrm{m}}, \mathrm{x}_{\mathrm{l}}\right) \rightarrow 0$ as $\mathrm{n}, \mathrm{m}, \mathrm{l} \rightarrow \infty$.

Definition 1.5 ([12]). A G-metric space $(X, G)$ is said to be G-complete if every G-Cauchy sequence in $(\mathrm{X}, \mathrm{G})$ is $\mathrm{G}$-convergent in $\mathrm{X}$.

Proposition 1.6 ([12]). Let (X, G) be a G-metric space. Then the following are equivalent.

(1) The sequence $\left\{x_{n}\right\}$ is G-Cauchy.

(2) For every $\epsilon>0$, there exists $\mathrm{k} \in \mathbb{N}$ such that $\mathrm{G}\left(\mathrm{x}_{\mathrm{n}}, \mathrm{x}_{\mathrm{m}}, \mathrm{x}_{\mathrm{m}}\right)<\epsilon$ for all $\mathrm{n}, \mathrm{m} \geqslant k$.

Proposition 1.7 ([12]). Let (X, G) be a $\mathrm{G}$-metric space. Then the function $\mathrm{G}(\mathrm{x}, \mathrm{y}, \mathrm{z})$ is jointly continuous in all three of its variables.

Definition $1.8([12])$. Let $(X, G)$ and $\left(X^{\prime}, G^{\prime}\right)$ be G-metric space, and $f:(X, G) \rightarrow\left(X^{\prime}, G^{\prime}\right)$ be a function. Then $f$ is said to be G-continuous at a point $a \in X$ if and only if for every $\varepsilon>0$, there is $\delta>0$ such that $x, y \in X$ and $G(a, x, y)<\delta$ implies $G^{\prime}(f(a), f(x), f(y))<\varepsilon$. A function $f$ is $G$-continuous at $X$ if and only if it is G-continuous at all $a \in X$.

Proposition 1.9 ([12]). Let $(\mathrm{X}, \mathrm{G})$ and $\left(\mathrm{X}^{\prime}, \mathrm{G}^{\prime}\right)$ be $\mathrm{G}$-metric spaces. Then $\mathrm{f}: \mathrm{X} \rightarrow \mathrm{X}^{\prime}$ is $\mathrm{G}$-continuous at $\mathrm{x} \in \mathrm{X}$ if and only if it is G-sequentially continuous at $x$, that is, whenever $\left\{x_{n}\right\}$ is G-convergent to $x,\left\{f\left(x_{n}\right)\right\}$ is G-convergent to $f(x)$.

Proposition 1.10 ([12]). Let (X, G) be a G-metric space. Then, for any $\mathrm{x}, \mathrm{y}, z$, a in $\mathrm{X}$ it follows that:

(i) if $\mathrm{G}(x, y, z)=0$, then $x=y=z$;

(ii) $G(x, y, z) \leqslant G(x, x, y)+G(x, x, z)$;

(iii) $G(x, y, y) \leqslant 2 G(y, x, x)$;

(iv) $G(x, y, z) \leqslant G(x, a, z)+G(a, y, z)$;

(v) $G(x, y, z) \leqslant \frac{2}{3}(G(x, y, a)+G(x, a, z)+G(a, y, z))$; 
(vi) $G(x, y, z) \leqslant G(x, a, a)+G(y, a, a)+G(z, a, a)$.

Recently, Jleli-Samet [8] and Samet et al. [13] observed that some fixed point theorems in the context of a G-metric space can be proved (by simple transformation) using related existing results in the setting of a (quasi-) metric space. Namely, if the contraction condition of the fixed point theorem on G-metric space can be reduced to two variables, then one can construct an equivalent fixed point theorem in setting of usual metric space. This idea is not completely new, but it was not successfully used before (see [11]). Very recently, Karapinar and Agarwal [9] suggested new contraction conditions in G-metric space in a way that the techniques in $[8,13]$ are not applicable. In this approach [9], contraction conditions cannot be expressed in two variables. So, in some cases, as is noticed even in Jleli-Samet's paper [8], when the contraction condition is of nonlinear type, this strategy cannot be always successfully used. This is exactly the case in our paper.

\section{Main results}

Theorem 2.1. Let $(\mathrm{X}, \mathrm{G})$ be a complete $\mathrm{G}$-metric space. Suppose the three self-mappings $\mathrm{f}, \mathrm{g}, \mathrm{h}: \mathrm{X} \rightarrow \mathrm{X}$ satisfy the following condition

$$
G^{\theta}(f x, g y, h z) \leqslant q G^{\alpha}(x, y, z) G^{\beta}(x, f x, f x) G^{\gamma}(y, g y, g y) G^{\delta}(z, h z, h z)
$$

for all $x, y, z \in X$, where $0 \leqslant q<1, \alpha, \beta, \gamma, \delta \in[0,+\infty)$ and $\theta=\alpha+\beta+\gamma+\delta$. Then $f, g$, and $\mathrm{h}$ have a unique common fixed point (say $\mathrm{u}$ ) and $\mathrm{f}, \mathrm{g}, \mathrm{h}$ are all $\mathrm{G}$-continuous at $\mathrm{u}$.

Proof. We will proceed in two steps. First we prove any fixed point of $f$ is a fixed point of $g$ and $h$. Assume that $p \in X$ is such that $f p=p$. Now, we prove that $p=g p=h p$. In fact, by using (2.1), we have

$$
G^{\theta}(f p, g p, h p) \leqslant q G^{\alpha}(p, p, p) G^{\beta}(p, f p, f p) G^{\gamma}(p, g p, g p) G^{\delta}(p, h p, h p)=0 .
$$

It follows that $G^{\theta}(p, g p, h p)=0$, hence, $p=g p=h p$. So $p$ is a common fixed point of $f, g$, and $h$. The same conclusion holds if $p=g p$ or $p=h p$.

Now, we prove that $f, g$, and $h$ have a unique common fixed point. Suppose $x_{0}$ is an arbitrary point in $X$. Define $\left\{x_{n}\right\}$ by $x_{3 n+1}=f x_{3 n}, x_{3 n+2}=g x_{3 n+1}, x_{3 n+3}=h x_{3 n+2}, n=0,1,2, \cdots$. If $x_{n}=x_{n+1}$ for some $n$, with $n=3 m$, then $p=x_{3 m}$ is a fixed point of $f$ and, by the first step, $p$ is a common fixed point for $f$, $g$, and $h$. The same holds if $n=3 m+1$ or $n=3 m+2$. Without loss of generality, we can assume that $x_{n} \neq x_{n+1}$ for all $n \in \mathbb{N}$.

Next we prove sequence $\left\{x_{n}\right\}$ is a G-Cauchy sequence. In fact, by (2.1) and (G3), we have

$$
\begin{aligned}
& G^{\theta}\left(x_{3 n+1}, x_{3 n+2}, x_{3 n+3}\right) \\
& \quad=G^{\Theta}\left(f x_{3 n}, g x_{3 n+1}, h x_{3 n+2}\right) \\
& \quad \leqslant q G^{\alpha}\left(x_{3 n}, x_{3 n+1}, x_{3 n+2}\right) G^{\beta}\left(x_{3 n}, f x_{3 n}, f x_{3 n}\right) G^{\gamma}\left(x_{3 n+1}, g x_{3 n+1}, g x_{3 n+1}\right) G^{\delta}\left(x_{3 n+2}, h x_{3 n+2}, h x_{3 n+2}\right) \\
& \quad=q G^{\alpha}\left(x_{3 n}, x_{3 n+1}, x_{3 n+2}\right) G^{\beta}\left(x_{3 n}, x_{3 n+1}, x_{3 n+1}\right) G^{\gamma}\left(x_{3 n+1}, x_{3 n+2}, x_{3 n+2}\right) G^{\delta}\left(x_{3 n+2}, x_{3 n+3}, x_{3 n+3}\right) \\
& \quad \leqslant q G^{\alpha}\left(x_{3 n}, x_{3 n+1}, x_{3 n+2}\right) G^{\beta}\left(x_{3 n}, x_{3 n+1}, x_{3 n+2}\right) G^{\gamma}\left(x_{3 n+1}, x_{3 n+2}, x_{3 n+3}\right) G^{\delta}\left(x_{3 n+1}, x_{3 n+2}, x_{3 n+3}\right) .
\end{aligned}
$$

Combining $\theta=\alpha+\beta+\gamma+\delta$, which implies that

$$
G^{(\alpha+\beta)}\left(x_{3 n+1}, x_{3 n+2}, x_{3 n+3}\right)=G^{(\theta-\gamma-\delta)}\left(x_{3 n+1}, x_{3 n+2}, x_{3 n+3}\right) \leqslant q G^{(\alpha+\beta)}\left(x_{3 n}, x_{3 n+1}, x_{3 n+2}\right) .
$$

If $\alpha+\beta=0$, then we have $1 \leqslant q$, it is a contradiction, hence $\alpha+\beta>0$. Thus, we have

$$
G\left(x_{3 n+1}, x_{3 n+2}, x_{3 n+3}\right) \leqslant q^{\frac{1}{\alpha+\beta}} G\left(x_{3 n}, x_{3 n+1}, x_{3 n+2}\right) .
$$


On the other hand, from the conditions (2.1) and (G3), we have

$$
\begin{aligned}
& \mathrm{G}^{\theta}\left(x_{3 n+2}, x_{3 n+3}, x_{3 n+4}\right) \\
& \quad=\mathrm{G}^{\theta}\left(f x_{3 n+3}, g x_{3 n+1}, h x_{3 n+2}\right) \\
& \quad \leqslant \mathrm{qG}^{\alpha}\left(x_{3 n+3}, x_{3 n+1}, x_{3 n+2}\right) \mathrm{G}^{\beta}\left(x_{3 n+3}, f x_{3 n+3}, f x_{3 n+3}\right) G^{\gamma}\left(x_{3 n+1}, g x_{3 n+1}, g x_{3 n+1}\right) G^{\delta}\left(x_{3 n+2}, h x_{3 n+2}, h x_{3 n+2}\right) \\
& \quad=\mathrm{qG}^{\alpha}\left(x_{3 n+3}, x_{3 n+1}, x_{3 n+2}\right) G^{\beta}\left(x_{3 n+3}, x_{3 n+4}, x_{3 n+4}\right) G^{\gamma}\left(x_{3 n+1}, x_{3 n+2}, x_{3 n+2}\right) G^{\delta}\left(x_{3 n+2}, x_{3 n+3}, x_{3 n+3}\right) \\
& \quad \leqslant q G^{\alpha}\left(x_{3 n+1}, x_{3 n+2}, x_{3 n+3}\right) G^{\beta}\left(x_{3 n+2}, x_{3 n+3}, x_{3 n+4}\right) G^{\gamma}\left(x_{3 n+1}, x_{3 n+2}, x_{3 n+3}\right) G^{\delta}\left(x_{3 n+2}, x_{3 n+3}, x_{3 n+4}\right) .
\end{aligned}
$$

If $\alpha+\gamma=0$, then we have $1 \leqslant \mathrm{q}$, which is a contradiction, hence $\alpha+\gamma>0$, which implies that

$$
G\left(x_{3 n+2}, x_{3 n+3}, x_{3 n+4}\right) \leqslant q^{\frac{1}{\alpha+\gamma}} G\left(x_{3 n+1}, x_{3 n+2}, x_{3 n+3}\right) .
$$

Again, using (2.1) and (G3), we can get

$$
\begin{aligned}
& \mathrm{G}^{\theta}\left(x_{3 n+3}, x_{3 n+4}, x_{3 n+5}\right) \\
& \quad=\mathrm{G}^{\theta}\left(f x_{3 n+3}, g x_{3 n+4}, h x_{3 n+2}\right) \\
& \quad \leqslant \mathrm{qG}^{\alpha}\left(x_{3 n+3}, x_{3 n+4}, x_{3 n+2}\right) \mathrm{G}^{\beta}\left(x_{3 n+3}, f x_{3 n+3}, f x_{3 n+3}\right) G^{\gamma}\left(x_{3 n+4}, g x_{3 n+4}, g x_{3 n+4}\right) G^{\delta}\left(x_{3 n+2}, h x_{3 n+2}, h x_{3 n+2}\right) \\
& \quad=\mathrm{qG}^{\alpha}\left(x_{3 n+3}, x_{3 n+4}, x_{3 n+2}\right) G^{\beta}\left(x_{3 n+3}, x_{3 n+4}, x_{3 n+4}\right) G^{\gamma}\left(x_{3 n+4}, x_{3 n+5}, x_{3 n+5}\right) G^{\delta}\left(x_{3 n+2}, x_{3 n+3}, x_{3 n+3}\right) \\
& \quad \leqslant q G^{\alpha}\left(x_{3 n+2}, x_{3 n+3}, x_{3 n+4}\right) G^{\beta}\left(x_{3 n+3}, x_{3 n+4}, x_{3 n+5}\right) G^{\gamma}\left(x_{3 n+3}, x_{3 n+4}, x_{3 n+5}\right) G^{\delta}\left(x_{3 n+2}, x_{3 n+3}, x_{3 n+4}\right) .
\end{aligned}
$$

If $\alpha+\delta=0$, then we have $1 \leqslant q$, which is a contradiction, hence $\alpha+\delta>0$. Thus, we have

$$
G\left(x_{3 n+3}, x_{3 n+4}, x_{3 n+5}\right) \leqslant q^{\frac{1}{\alpha+\delta}} G\left(x_{3 n+2}, x_{3 n+3}, x_{3 n+4}\right) .
$$

Letting $t=\max \left\{\mathbf{q}^{\frac{1}{\alpha+\beta}}, \mathbf{q}^{\frac{1}{\alpha+\gamma}}, \mathbf{q}^{\frac{1}{\alpha+\delta}}\right\}$, then $0 \leqslant \mathrm{t}<1$. And combining (2.2), (2.3), and (2.4), we have

$$
G\left(x_{n}, x_{n+1}, x_{n+2}\right) \leqslant t G\left(x_{n-1}, x_{n}, x_{n+1}\right) \leqslant \cdots \leqslant t^{n} G\left(x_{0}, x_{1}, x_{2}\right) .
$$

Thus, by (G3) and (G5), for every $m, n \in \mathbb{N}, m>n$, noting that $0 \leqslant t<1$, we have

$$
\begin{aligned}
G\left(x_{n}, x_{m}, x_{m}\right) & \leqslant G\left(x_{n}, x_{n+1}, x_{n+1}\right)+G\left(x_{n+1}, x_{n+2}, x_{n+2}\right)+\cdots+G\left(x_{m-1}, x_{m}, x_{m}\right) \\
& \leqslant G\left(x_{n}, x_{n+1}, x_{n+2}\right)+G\left(x_{n+1}, x_{n+2}, x_{n+3}\right)+\cdots+G\left(x_{m-1}, x_{m}, x_{m+1}\right) \\
& \leqslant\left(t^{n}+t^{n+1}+\cdots+t^{m-1}\right) G\left(x_{0}, x_{1}, x_{2}\right) \\
& \leqslant \frac{t^{n}}{1-t} G\left(x_{0}, x_{1}, x_{2}\right) \rightarrow 0(n \rightarrow \infty),
\end{aligned}
$$

which implies that $G\left(x_{n}, x_{m}, x_{m}\right) \rightarrow 0$, as $n, m \rightarrow \infty$. Thus $\left\{x_{n}\right\}$ is a G-Cauchy sequence. Due to the G-completeness of $X$, there exists $u \in X$, such that $\left\{x_{n}\right\}$ is G-convergent to $u$.

Now we prove $u$ is a common fixed point of $f, g$, and $h$. By using (2.1), we have

$$
\begin{aligned}
\mathrm{G}^{\Theta}\left(f u, x_{3 n+2}, x_{3 n+3}\right) & =G^{\theta}\left(f u, g x_{3 n+1}, h x_{3 n+2}\right) \\
& \leqslant q G^{\alpha}\left(u, x_{3 n+1}, x_{3 n+2}\right) G^{\beta}(u, f u, f u) G^{\gamma}\left(x_{3 n+1}, x_{3 n+2}, x_{3 n+2}\right) G^{\delta}\left(x_{3 n+2}, x_{3 n+3}, x_{3 n+3}\right) .
\end{aligned}
$$

Letting $n \rightarrow \infty$, and using the fact that $G$ is continuous in its variables, we can get

$$
\mathrm{G}^{\theta}(\mathrm{fu}, \mathrm{u}, \mathrm{u})=0,
$$

which gives that $f u=u$, hence $u$ is a fixed point of $f$.

Similarly it can be shown that $g u=u$ and $h u=u$. Consequently, we have $u=f u=g u=h u$, and $u$ is a common fixed point of $f, g$, and $h$. 
To prove the uniqueness, suppose that $v$ is another common fixed point of $f, g$, and $h$, then by (2.1), we have

$$
G^{\theta}(u, u, v)=G^{\theta}(f u, g u, h v) \leqslant q G^{\alpha}(u, u, v) G^{\beta}(u, f u, f u) G^{\gamma}(u, g u, g u) G^{\delta}(v, h v, h v)=0 .
$$

Hence, $u=v$. Thus $u$ is a unique common fixed point of $f, g$, and $h$.

To show that $f$ is $G$-continuous at $u$, let $\left\{y_{n}\right\}$ be any sequence in $X$ such that $\left\{y_{n}\right\}$ is G-convergent to $u$. For $n \in \mathbb{N}$, from (2.1) we have

$$
G^{\theta}\left(f y_{n}, u, u\right)=G^{\theta}\left(f y_{n}, g u, h u\right) \leqslant q G^{\alpha}\left(y_{n}, u, u\right) G^{\beta}\left(y_{n}, f y_{n}, f y_{n}\right) G^{\gamma}(u, g u, g u) G^{\delta}(u, h u, h u)=0 .
$$

Therefore, we get $\lim _{n \rightarrow \infty} G\left(f y_{n}, u, u\right)=0$, that is, $\left\{f y_{n}\right\}$ is G-convergent to $u=f u$, and so $f$ is Gcontinuous at $u$. Similarly, we can also prove that $g$, $h$ are $G$-continuous at $u$. This completes the proof of Theorem 2.1.

Corollary 2.2. Let $(\mathrm{X}, \mathrm{G})$ be a complete $\mathrm{G}$-metric space. Suppose the three self-mappings $\mathrm{f}, \mathrm{g}, \mathrm{h}: \mathrm{X} \rightarrow \mathrm{X}$ satisfy the condition

$$
G^{\theta}\left(f^{p} x, g^{s} y, h^{r} z\right) \leqslant q G^{\alpha}(x, y, z) G^{\beta}\left(x, f^{p} x, f^{p} x\right) G^{\gamma}\left(y, g^{s} y, g^{s} y\right) G^{\delta}\left(z, h^{r} z, h^{r} z\right)
$$

for all $x, y, z \in X$, where $0 \leqslant q<1, p, s, r \in \mathbb{N}, \alpha, \beta, \gamma, \delta \in[0,+\infty)$ and $\theta=\alpha+\beta+\gamma+\delta$. Then $f, g$, and $h$ have a unique common fixed point (say $\mathrm{u}$ ) and $\mathrm{f}^{\mathrm{p}}, \mathrm{g}^{\mathrm{s}}$, and $\mathrm{h}^{\mathrm{r}}$ are all $\mathrm{G}$-continuous at $\mathrm{u}$.

Proof. From Theorem 2.1 we know that $f^{p}, g^{s}, h^{r}$ have a unique common fixed point (say $u$ ), that is, $f^{p} u=g^{s} u=h^{r} u=u$, and $f^{p}, g^{s}, h^{r}$ are G-continuous at $u$. Since $f u=f f^{p} u=f^{p+1} u=f^{p} f u$, so $f u$ is another fixed point of $f^{p}, g u=g g^{s} u=g^{s+1} u=g^{s} g u$, so $g u$ is another fixed point of $g^{s}$, and $h u=h h^{r} u=h^{r+1} u=h^{r} h u$, so $h u$ is another fixed point of $h^{r}$. By the condition (2.5), we have

$$
G^{\theta}\left(f^{p} f u, g^{s} f u, h^{r} f u\right) \leqslant q G^{\alpha}(f u, f u, f u) G^{\beta}\left(f u, f^{p} f u, f^{p} f u\right) G^{\gamma}\left(f u, g^{s} f u, g^{s} f u\right) G^{\delta}\left(f u, h^{r} f u, h^{r} f u\right)=0,
$$

which implies that $G^{\theta}\left(f^{p} f u, g^{s} f u, h^{r} f u\right)=0$, that is $f u=f^{p} f u=g^{s} f u=h^{r} f u$, hence fu is another common fixed point of $f^{p}, g^{s}$, and $h^{r}$. Since the common fixed point of $f^{p}, g^{s}$, and $h^{r}$ is unique, we deduce that $u=f u$. By the same argument, we can prove $u=g u, u=f u$. Thus, we have $u=f u=g u=h u$. Suppose $v$ is another common fixed point of $f, g$, and $h$, then $v=f^{p} v$, and by using the condition (2.5) again, we have

$$
G^{\theta}(v, u, u)=G^{\theta}\left(f^{p} v, g^{s} u, h^{r} u\right) \leqslant q G^{\alpha}(v, u, u) G^{\beta}\left(v, f^{p} v, f^{p} v\right) G^{\gamma}\left(u, g^{s} u, g^{s} u\right) G^{\delta}\left(u, h^{r} u, h^{r} u\right)=0,
$$

which implies that $\mathrm{G}^{\theta}(v, u, u)=0$, hence $v=u$. So the common fixed of $f, g$, and $h$ is unique.

Corollary 2.3. Let $(\mathrm{X}, \mathrm{G})$ be a complete $\mathrm{G}$-metric space. Suppose self-mapping $\mathrm{T}: \mathrm{X} \rightarrow \mathrm{X}$ satisfies the condition:

$$
G^{\theta}(T x, T y, T z) \leqslant q G^{\alpha}(x, y, z) G^{\beta}(x, T x, T x) G^{\gamma}(y, T y, T y) G^{\delta}(z, T z, T z)
$$

for all $x, y, z \in X$, where $0 \leqslant q<1, \alpha, \beta, \gamma, \delta \in[0,+\infty)$ and $\theta=\alpha+\beta+\gamma+\delta$. Then $\mathrm{T}$ has a unique fixed point (say $\mathrm{u}$ ) and $\mathrm{T}$ is $\mathrm{G}$-continuous at $\mathrm{u}$.

Proof. Let $\mathrm{T}=\mathrm{f}=\mathrm{g}=\mathrm{h}$ in Theorem 2.1, we can know that Corollary 2.3 holds.

Corollary 2.4. Let $(\mathrm{X}, \mathrm{G})$ be a complete $\mathrm{G}$-metric space. Suppose self-mapping $\mathrm{T}: \mathrm{X} \rightarrow \mathrm{X}$ satisfies the condition:

$$
G^{\theta}\left(T^{p} x, T^{p} y, T^{p} z\right) \leqslant q G^{\alpha}(x, y, z) G^{\beta}\left(x, T^{p} x, T^{p} x\right) G^{\gamma}\left(y, T^{p} y, T^{p} y\right) G^{\delta}\left(z, T^{p} z, T^{p} z\right)
$$

for all $x, y, z \in X$, where $0 \leqslant q<1, p \in \mathbb{N}, \alpha, \beta, \gamma, \delta \in[0,+\infty)$ and $\theta=\alpha+\beta+\gamma+\delta$. Then $\mathrm{T}$ has a unique fixed point (say $\mathrm{u}$ ) and $\mathrm{T}^{\mathrm{p}}$ is $\mathrm{G}$-continuous at $\mathrm{u}$. 
Proof. Let $\mathrm{T}=\mathrm{f}=\mathrm{g}=\mathrm{h}$ and $\mathrm{p}=\mathrm{s}=\mathrm{r}$ in Corollary 2.2, we can get this conclusion holds.

Now we list some special cases of Theorem 2.1, and we get some corollaries in the sequel.

Corollary 2.5. Let $(\mathrm{X}, \mathrm{G})$ be a complete $\mathrm{G}$-metric space. Suppose $\mathrm{f}, \mathrm{g}$, and $\mathrm{h}$ are three mappings of $\mathrm{X}$ into itself. If one of the following conditions is satisfied

(1) $G(f x, g y, h z) \leqslant q G(x, y, z)$;

(2) $G(f x, g y, h z) \leqslant q G(x, f x, f x)$;

(3) $G(f x, g y, h z) \leqslant q G(y, g y, g y)$;

(4) $G(f x, g y, h z) \leqslant q G(z, h z, h z)$

for all $x, y, z \in X$, where $0 \leqslant q<1$, then $f, g$, and $h$ have a unique common fixed point (say $u$ ) and $f, g, h$ are all $\mathrm{G}$-continuous at $\mathrm{u}$.

Proof. Taking (1) $\alpha=1$ and $\beta=\gamma=\delta=0$; (2) $\beta=1$ and $\alpha=\gamma=\delta=0$; (3) $\gamma=1$ and $\alpha=\beta=\delta=0$; (4) $\delta=1$ and $\alpha=\beta=\gamma=0$ in Theorem 2.1, respectively, then the conclusion of Corollary 2.5 can be obtained from Theorem 2.1 immediately.

Corollary 2.6. Let $(\mathrm{X}, \mathrm{G})$ be a complete $\mathrm{G}$-metric space. Suppose $\mathrm{f}, \mathrm{g}$, and $\mathrm{h}$ are three mappings of $\mathrm{X}$ into itself. If one of the following conditions is satisfied

(1) $G^{2}(f x, g y, h z) \leqslant q G(x, y, z) G(x, f x, f x)$;

(2) $G^{2}(f x, g y, h z) \leqslant q G(x, y, z) G(y, g y, g y)$;

(3) $G^{2}(f x, g y, h z) \leqslant q G(x, y, z) G(z, h z, h z)$;

(4) $G^{2}(f x, g y, h z) \leqslant q G(x, f x, f x) G(y, g y, g y)$;

(5) $\mathrm{G}^{2}(\mathrm{f} x, \mathrm{gy}, \mathrm{hz}) \leqslant \mathrm{qG}(y, g y, g y) \mathrm{G}(z, h z, h z)$;

(6) $G^{2}(f x, g y, h z) \leqslant q G(z, h z, h z) G(x, f x, f x)$

for all $\mathrm{x}, \mathrm{y}, z \in \mathrm{X}$, where $0 \leqslant \mathrm{q}<1$, then $\mathrm{f}, \mathrm{g}$, and $\mathrm{h}$ have a unique common fixed point (say $\mathrm{u}$ ) and $\mathrm{f}, \mathrm{g}, \mathrm{h}$ are all $\mathrm{G}$-continuous at $\mathrm{u}$.

Proof. Taking (1) $\alpha=\beta=1$ and $\gamma=\delta=0$; (2) $\alpha=\gamma=1$ and $\beta=\delta=0$; (3) $\alpha=\delta=1$ and $\beta=\gamma=0$; (4) $\beta=\delta=1$ and $\alpha=\gamma=0$; (5) $\gamma=\delta=1$ and $\alpha=\beta=0$; (6) $\beta=\gamma=1$ and $\alpha=\delta=0$ in Theorem 2.1, respectively, then the conclusion of Corollary 2.6 can be obtained from Theorem 2.1 immediately.

Corollary 2.7. Let (X, G) be a complete G-metric space. Suppose $\mathrm{f}, \mathrm{g}$, and $\mathrm{h}$ are three mappings of $\mathrm{X}$ into itself. If one of the following conditions is satisfied

(1) $G^{3}(f x, g y, h z) \leqslant q G(x, y, z) G(x, f x, f x) G(y, g y, g y)$;

(2) $G^{3}(f x, g y, h z) \leqslant q G(x, y, z) G(x, f x, f x) G(z, h z, h z)$;

(3) $\mathrm{G}^{3}(f x, g y, h z) \leqslant q G(x, y, z) G(y, g y, g y) G(z, h z, h z)$;

(4) $G^{3}(f x, g y, h z) \leqslant q G(x, f x, f x) G(y, g y, g y) G(z, h z, h z)$

for all $\mathrm{x}, \mathrm{y}, z \in \mathrm{X}$, where $0 \leqslant \mathrm{q}<1$, then $\mathrm{f}, \mathrm{g}$, and $\mathrm{h}$ have a unique common fixed point (say $\mathrm{u}$ ) and $\mathrm{f}, \mathrm{g}$, $\mathrm{h}$ are all $\mathrm{G}$-continuous at $\mathrm{u}$.

Proof. Taking (1) $\delta=0$ and $\alpha=\beta=\gamma=1$; (2) $\gamma=0$ and $\alpha=\beta=\delta=1$; (3) $\beta=0$ and $\alpha=\gamma=\delta=1$; (4) $\alpha=0$ and $\beta=\gamma=\delta=1$ in Theorem 2.1, respectively, then the conclusion of Corollary 2.7 can be obtained from Theorem 2.1 immediately.

Corollary 2.8. Let $(\mathrm{X}, \mathrm{G})$ be a complete $\mathrm{G}$-metric space. Suppose the three self-mappings $\mathrm{f}, \mathrm{g}, \mathrm{h}: \mathrm{X} \rightarrow \mathrm{X}$ satisfy the following condition:

$$
G^{4}(f x, g y, h z) \leqslant q G(x, y, z) G(x, f x, f x) G(y, g y, g y) G(z, h z, h z)
$$

for all $\mathrm{x}, \mathrm{y}, z \in \mathrm{X}$, where $0 \leqslant \mathrm{q}<1$. Then $\mathrm{f}, \mathrm{g}$, and $\mathrm{h}$ have a unique common fixed point (say $\mathrm{u}$ ) and $\mathrm{f}, \mathrm{g}, \mathrm{h}$ are all $\mathrm{G}$-continuous at $\mathrm{u}$. 
Proof. Taking $\alpha=\beta=\gamma=\delta=1$ in Theorem 2.1, then the conclusion of Corollary 2.8 can be obtained from Theorem 2.1 immediately.

Theorem 2.9. Let $(\mathrm{X}, \mathrm{G})$ be a complete $\mathrm{G}$-metric space, and let $\mathrm{f}, \mathrm{g}, \mathrm{h}: \mathrm{X} \rightarrow \mathrm{X}$ be three self-mappings in $\mathrm{X}$, which satisfy the following condition

$$
G^{\theta}(f x, g y, h z) \leqslant q G^{\alpha}(x, y, z) G^{\beta}(x, f x, g y) G^{\gamma}(y, g y, h z) G^{\delta}(z, h z, f x)
$$

for all $x, y, z \in X$, where $0 \leqslant q<1, \theta=\alpha+\beta+\gamma+\delta, \alpha, \beta, \gamma, \delta \in[0,+\infty)$. Then $f, g$, and $\mathrm{h}$ have a unique common fixed point (say $\mathrm{u}$ ), and $\mathrm{f}, \mathrm{g}, \mathrm{h}$ are all $\mathrm{G}$-continuous at $\mathrm{u}$.

Proof. We will proceed in two steps. First we prove any fixed point of $f$ is a fixed point of $g$ and $h$. Assume that $p \in X$ such that $f p=p$, by the condition (2.6), we have

$$
G^{\Theta}(f p, g p, h p) \leqslant q G^{\alpha}(p, p, p) G^{\beta}(p, f p, g p) G^{\gamma}(p, g p, h p) G^{\delta}(p, h p, f p)=0 .
$$

It follows that $G^{\theta}(p, g p, h p)=0$, hence, $p=g p=h p$. So $p$ is a common fixed point of $f, g$, and $h$. The same conclusion holds if $p=g p$ or $p=h p$.

Now, we prove that $f, g$, and $h$ have a unique common fixed point. Suppose $x_{0}$ is an arbitrary point in $x$. Define $\left\{x_{n}\right\}$ by $x_{3 n+1}=f x_{3 n}, x_{3 n+2}=g x_{3 n+1}, x_{3 n+3}=h x_{3 n+2}, n=0,1,2, \cdots$. If $x_{n}=x_{n+1}$ for some $n$, with $n=3 m$, then $p=x_{3 m}$ is a fixed point of $f$ and, by the first step, $p$ is a common fixed point for $f$, $g$, and $h$. The same holds if $n=3 m+1$ or $n=3 m+2$. Without loss of generality, we can assume that $x_{n} \neq x_{n+1}$ for all $n \in \mathbb{N}$.

Next we prove the sequence $\left\{x_{n}\right\}$ is a G-Cauchy sequence. In fact, by (2.6) and (G3), we can have

$$
\begin{aligned}
& G^{\theta}\left(x_{3 n+1}, x_{3 n+2}, x_{3 n+3}\right) \\
& \quad=G^{\theta}\left(f x_{3 n}, g x_{3 n+1}, h x_{3 n+2}\right) \\
& \quad \leqslant q G^{\alpha}\left(x_{3 n}, x_{3 n+1}, x_{3 n+2}\right) G^{\beta}\left(x_{3 n}, f x_{3 n}, g x_{3 n+1}\right) G^{\gamma}\left(x_{3 n+1}, g x_{3 n+1}, h x_{3 n+2}\right) G^{\delta}\left(x_{3 n+2}, h x_{3 n+2}, f x_{3 n}\right) \\
& \quad=q G^{\alpha}\left(x_{3 n}, x_{3 n+1}, x_{3 n+2}\right) G^{\beta}\left(x_{3 n}, x_{3 n+1}, x_{3 n+2}\right) G^{\gamma}\left(x_{3 n+1}, x_{3 n+2}, x_{3 n+3}\right) G^{\delta}\left(x_{3 n+2}, x_{3 n+3}, x_{3 n+1}\right) \\
& \quad \leqslant q G^{\alpha}\left(x_{3 n}, x_{3 n+1}, x_{3 n+2}\right) G^{\beta}\left(x_{3 n}, x_{3 n+1}, x_{3 n+2}\right) G^{\gamma}\left(x_{3 n+1}, x_{3 n+2}, x_{3 n+3}\right) G^{\delta}\left(x_{3 n+1}, x_{3 n+2}, x_{3 n+3}\right),
\end{aligned}
$$

which gives that

$$
G\left(x_{3 n+1}, x_{3 n+2}, x_{3 n+3}\right) \leqslant q^{\frac{1}{\alpha+\beta}} G\left(x_{3 n}, x_{3 n+1}, x_{3 n+2}\right) .
$$

By the same argument, we can get

$$
\begin{aligned}
& G\left(x_{3 n+2}, x_{3 n+3}, x_{3 n+4}\right) \leqslant q^{\frac{1}{\alpha+\gamma}} G\left(x_{3 n+1}, x_{3 n+2}, x_{3 n+3}\right), \\
& G\left(x_{3 n+3}, x_{3 n+4}, x_{3 n+5}\right) \leqslant q^{\frac{1}{\alpha+\delta}} G\left(x_{3 n+2}, x_{3 n+3}, x_{3 n+4}\right) .
\end{aligned}
$$

Letting $t=\max \left\{q^{\frac{1}{\alpha+\beta}}, q^{\frac{1}{\alpha+\gamma}}, q^{\frac{1}{\alpha+\delta}}\right\}$, hence $0 \leqslant t<1$, then for all $n$, we have

$$
G\left(x_{n}, x_{n+1}, x_{n+2}\right) \leqslant t G\left(x_{n-1}, x_{n}, x_{n+1}\right) \leqslant \cdots \leqslant t^{n} G\left(x_{0}, x_{1}, x_{2}\right) .
$$

Thus, by (G3) and (G5), for every $m, n \in \mathbb{N}, m>n$, noting that $0 \leqslant t<1$, we have

$$
\begin{aligned}
G\left(x_{n}, x_{m}, x_{m}\right) & \leqslant G\left(x_{n}, x_{n+1}, x_{n+1}\right)+G\left(x_{n+1}, x_{n+2}, x_{n+2}\right)+\cdots+G\left(x_{m-1}, x_{m}, x_{m}\right) \\
& \leqslant G\left(x_{n}, x_{n+1}, x_{n+2}\right)+G\left(x_{n+1}, x_{n+2}, x_{n+3}\right)+\cdots+G\left(x_{m-1}, x_{m}, x_{m+1}\right) \\
& \leqslant\left(t^{n}+t^{n+1}+\cdots+t^{m-1}\right) G\left(x_{0}, x_{1}, x_{2}\right) \\
& \leqslant \frac{t^{n}}{1-t} G\left(x_{0}, x_{1}, x_{2}\right) \rightarrow 0(n \rightarrow \infty),
\end{aligned}
$$


which gives that $G\left(x_{n}, x_{m}, x_{m}\right) \rightarrow 0$, as $n, m \rightarrow \infty$. Thus $\left\{x_{n}\right\}$ is G-Cauchy sequence. Due to the completeness of $X$, there exists $u \in X$, such that $\left\{x_{n}\right\}$ is G-convergent to $u$.

Next we prove $u$ is a common fixed point of $f, g$, and $h$. It follows from (2.6) that

$$
\begin{aligned}
& \mathrm{G}^{\theta}\left(f u, x_{3 n+2}, x_{3 n+3}\right) \\
& \quad=G^{\theta}\left(f u, g x_{3 n+1}, h x_{3 n+2}\right) \\
& \quad \leqslant q G^{\alpha}\left(u, x_{3 n+1}, x_{3 n+2}\right) G^{\beta}\left(u, f u, g x_{3 n+1}\right) G^{\gamma}\left(x_{3 n+1}, g x_{3 n+1}, h x_{3 n+2}\right) G^{\delta}\left(x_{3 n+2}, h x_{3 n+2}, f u\right) \\
& \quad=q G^{\alpha}\left(u, x_{3 n+1}, x_{3 n+2}\right) G^{\beta}\left(u, f u, x_{3 n+2}\right) G^{\gamma}\left(x_{3 n+1}, x_{3 n+2}, x_{3 n+3}\right) G^{\delta}\left(x_{3 n+2}, x_{3 n+3}, f u\right) .
\end{aligned}
$$

Letting $n \rightarrow \infty$, and using the fact that $G$ is continuous in its variables, we get that

$$
\mathrm{G}^{\theta}(\mathrm{fu}, \mathrm{u}, \mathrm{u})=0 .
$$

Similarly, we can obtain that $G^{\theta}(u, g u, u)=0, G^{\theta}(u, u, h u)=0$. Hence, we get $u=f u=g u=h u$, and $u$ is a common fixed point of $f, g$, and $h$. Suppose $v$ is another common fixed point of $f, g$ and $h$, then by (2.6) we have

$$
\mathrm{G}^{\theta}(u, u, v)=\mathrm{G}^{\theta}(\mathrm{fu}, \mathrm{gu}, \mathrm{hv}) \leqslant q \mathrm{G}^{\alpha}(u, u, v) \mathrm{G}^{\beta}(u, f u, g u) \mathrm{G}^{\gamma}(u, g u, h v) \mathrm{G}^{\delta}(v, h v, f u)=0 .
$$

Thus, $u=v$. Then we know that the common fixed point of $f, g$, and $h$ is unique.

To show that $f$ is $G$-continuous at $u$, let $\left\{y_{n}\right\}$ be any sequence in $X$ such that $\left\{y_{n}\right\}$ is G-convergent to $u$. For $n \in \mathbb{N}$, from (2.6) we have

$$
G^{\theta}\left(f y_{n}, u, u\right)=G^{\theta}\left(f y_{n}, g u, h u\right) \leqslant q G^{\alpha}\left(y_{n}, u, u\right) G^{\beta}\left(y_{n}, f y_{n}, g u\right) G^{\gamma}(u, g u, h u) G^{\delta}\left(u, h u, f y_{n}\right)=0,
$$

which implies that $\lim _{n \rightarrow \infty} G^{\theta}\left(f y_{n}, u, u\right)=0$. Hence $\left\{f y_{n}\right\}$ is G-convergent to $u=f u$. So $f$ is $G$ continuous at $u$. Similarly, we can also prove that $g, h$ are $G$-continuous at $u$. This completes the proof of Theorem 2.9.

Corollary 2.10. Let $(\mathrm{X}, \mathrm{G})$ be a complete $\mathrm{G}$-metric space, and let $\mathrm{f}, \mathrm{g}, \mathrm{h}: \mathrm{X} \rightarrow \mathrm{X}$ be three self-mappings in $\mathrm{X}$, which satisfy the following condition

$$
G^{\theta}\left(f^{m} x, g^{n} y, h^{l} z\right) \leqslant q G^{\alpha}(x, y, z) G^{\beta}\left(x, f^{m} x, g^{n} y\right) G^{\gamma}\left(y, g^{n} y, h^{l} z\right) G^{\delta}\left(z, h^{l} z, f^{m} x\right)
$$

for all $x, y, z \in X$, where $0 \leqslant q<1, m, n, l \in \mathbb{N}, \alpha, \beta, \gamma, \delta \in[0,+\infty)$ and $\theta=\alpha+\beta+\gamma+\delta$. Then $f, g$, and $h$ have a unique common fixed point (say $\mathrm{u}$ ), and $\mathrm{f}^{\mathrm{m}}, \mathrm{g}^{\mathrm{n}}, \mathrm{h}^{\mathrm{l}}$ are all $\mathrm{G}$-continuous at $\mathrm{u}$.

Corollary 2.11. Let $(\mathrm{X}, \mathrm{G})$ be a complete $\mathrm{G}$-metric space, and let $\mathrm{T}: \mathrm{X} \rightarrow \mathrm{X}$ be a self-mapping in $\mathrm{X}$, which satisfies the following condition

$$
\mathrm{G}^{\theta}(T x, T y, T z) \leqslant q G^{\alpha}(x, y, z) G^{\beta}(x, T x, T y) G^{\gamma}(y, T y, T z) G^{\delta}(z, T z, T x)
$$

for all $x, y, z \in X$, where $0 \leqslant q<1, \alpha, \beta, \gamma, \delta \in[0,+\infty)$ and $\theta=\alpha+\beta+\gamma+\delta$. Then $T$ has a unique fixed point (say $\mathrm{u}$ ), and $\mathrm{T}$ is $\mathrm{G}$-continuous at $\mathrm{u}$.

Now, we list some special cases of Theorem 2.9, and we get some corollaries in the sequel.

Corollary 2.12. Let $(\mathrm{X}, \mathrm{G})$ be a complete $\mathrm{G}$-metric space. Suppose $\mathrm{f}, \mathrm{g}$, and $\mathrm{h}$ are three mappings of $\mathrm{X}$ into itself. If one of the following conditions is satisfied

(1) $G(f x, g y, h z) \leqslant q G(x, y, z)$;

(2) $G(f x, g y, h z) \leqslant q G(x, f x, g y)$;

(3) $G(f x, g y, h z) \leqslant q G(y, g y, h z)$;

(4) $\mathrm{G}(\mathrm{fx}, \mathrm{gy}, \mathrm{hz}) \leqslant \mathrm{qG}(z, \mathrm{~h} z, \mathrm{fx})$

for all $x, y, z \in X$, where $0 \leqslant q<1$, then $f, g$, and $h$ have a unique common fixed point (say $u$ ) and $f, g, h$ are all $\mathrm{G}$-continuous at $\mathrm{u}$. 
Corollary 2.13. Let $(\mathrm{X}, \mathrm{G})$ be a complete $\mathrm{G}$-metric space. Suppose $\mathrm{f}, \mathrm{g}$, and $\mathrm{h}$ are three mappings of $\mathrm{X}$ into itself. If one of the following conditions is satisfied

(1) $\mathrm{G}^{2}(f x, g y, h z) \leqslant q G(x, y, z) G(x, f x, g y)$;

(2) $G^{2}(f x, g y, h z) \leqslant q G(x, y, z) G(y, g y, h z)$;

(3) $\mathrm{G}^{2}(f x, g y, h z) \leqslant q G(x, y, z) G(z, h z, f x)$;

(4) $G^{2}(f x, g y, h z) \leqslant q G(x, f x, g y) G(y, g y, h z)$;

(5) $G^{2}(f x, g y, h z) \leqslant q G(y, g y, h z) G(z, h z, f x)$;

(6) $G^{2}(f x, g y, h z) \leqslant q G(x, f x, g y) G(z, h z, f x)$

for all $\mathrm{x}, \mathrm{y}, z \in \mathrm{X}$, where $0 \leqslant \mathrm{q}<1$, then $\mathrm{f}, \mathrm{g}$, and $\mathrm{h}$ have a unique common fixed point (say $\mathrm{u}$ ) and $\mathrm{f}, \mathrm{g}, \mathrm{h}$ are all G-continuous at $\mathrm{u}$.

Corollary 2.14. Let $(\mathrm{X}, \mathrm{G})$ be a complete $\mathrm{G}$-metric space. Suppose $\mathrm{f}, \mathrm{g}$, and $\mathrm{h}$ are three mappings of $\mathrm{X}$ into itself. If one of the following conditions is satisfied

(1) $G^{3}(f x, g y, h z) \leqslant q G(x, y, z) G(x, f x, g y) G(y, g y, h z)$;

(2) $G^{3}(f x, g y, h z) \leqslant q G(x, y, z) G(x, f x, g y) G(z, h z, f x)$;

(3) $G^{3}(f x, g y, h z) \leqslant q G(x, y, z) G(y, g y, h z) G(z, h z, f x)$;

(4) $G^{3}(f x, g y, h z) \leqslant q G(x, f x, g y) G(y, g y, h z) G(z, h z, f x)$

for all $x, y, z \in X$, where $0 \leqslant q<1$, then $f, g$, and $h$ have a unique common fixed point (say $u$ ) and $f, g$, $h$ are all G-continuous at $\mathrm{u}$.

Corollary 2.15. Let $(\mathrm{X}, \mathrm{G})$ be a complete $\mathrm{G}$-metric space. Suppose the three self-mappings $\mathrm{f}, \mathrm{g}, \mathrm{h}: \mathrm{X} \rightarrow \mathrm{X}$ satisfy the following condition:

$$
G^{4}(f x, g y, h z) \leqslant q G(x, y, z) G(x, f x, g y) G(y, g y, h z) G(z, h z, f x)
$$

for all $\mathrm{x}, \mathrm{y}, \mathrm{z} \in \mathrm{X}$, where $0 \leqslant \mathrm{q}<1$. Then $\mathrm{f}, \mathrm{g}$, and $\mathrm{h}$ have a unique common fixed point (say $\mathrm{u}$ ) and $\mathrm{f}, \mathrm{g}$, and $\mathrm{h}$ are all G-continuous at $\mathrm{u}$.

Now, we introduce an example to support the validity of our results.

Example 2.16. Let $X=\{0,1,2\}$ be a set with G-metric defined by Table 1 .

Table 1

\begin{tabular}{lc}
\hline$(x, y, z)$ & $\mathrm{G}(x, y, z)$ \\
\hline$(0,0,0),(1,1,1),(2,2,2)$ & 0 \\
$(0,0,1),(0,1,0),(1,0,0),(0,1,1),(1,0,1),(1,1,0)$ & 1 \\
$(1,2,2),(2,1,2),(2,2,1)$, & 2 \\
$(0,0,2),(0,2,0),(2,0,0),(0,2,2),(2,0,2),(2,2,0)$ & 3 \\
$(1,1,2),(1,2,1),(2,1,1),(0,1,2),(0,2,1),(1,0,2),(1,2,0),(2,0,1),(2,1,0)$ & 4 \\
\hline
\end{tabular}

Note that $G$ is non-symmetric as $G(1,2,2) \neq G(1,1,2)$. Let $f, g, h: X \rightarrow X$ be defined by Table 2 .

Table 2

\begin{tabular}{cccc}
\hline$x$ & $f(x)$ & $g(x)$ & $h(x)$ \\
\hline 0 & 2 & 1 & 2 \\
1 & 2 & 2 & 2 \\
2 & 2 & 2 & 2 \\
\hline
\end{tabular}


Case 1. If $y \neq 0$, we have $f x=g y=h z=2$, then

$$
G^{2}(f x, g y, h z)=G^{2}(2,2,2)=0 \leqslant \frac{1}{2} G(x, f x, g y) G(y, g y, h z) .
$$

Case 2. If $y=0$, then $f x=h z=2$ and $g y=1$, hence $G^{2}(f x, g y, h z)=G^{2}(2,1,2)=2^{2}=4$. We divide the study in three sub-cases:

(a) If $(x, y, z)=(0,0, z), z \in\{0,1,2\}$, then we have

$$
G(x, f x, g y) G(y, g y, h z)=G(0, f 0, g 0) G(0, g 0, h z)=G(0,2,1) G(0,1,2)=16 .
$$

Thus, we have

$$
\mathrm{G}^{2}(\mathrm{fx}, \mathrm{gy}, \mathrm{hz})=4<\frac{1}{2} \cdot 16=\frac{1}{2} \mathrm{G}(\mathrm{x}, \mathrm{fx}, \mathrm{gy}) \mathrm{G}(\mathrm{y}, \mathrm{gy}, \mathrm{hz}) .
$$

(b) If $(x, y, z)=(1,0, z), z \in\{0,1,2\}$, then we have

$$
\mathrm{G}(x, f x, g y) G(y, g y, h z)=G(1, f 1, g 0) G(0, g 0, h z)=G(1,2,1) G(0,1,2)=16 .
$$

Thus, we have

$$
\mathrm{G}^{2}(\mathrm{fx}, \mathrm{gy}, \mathrm{hz})=4<\frac{1}{2} \cdot 16=\frac{1}{2} \mathrm{G}(\mathrm{x}, \mathrm{f} x, \mathrm{gy}) \mathrm{G}(\mathrm{y}, \mathrm{gy}, \mathrm{hz}) .
$$

(c) If $(x, y, z)=(2,0, z), z \in\{0,1,2\}$, then we have

$$
G(x, f x, g y) G(y, g y, h z)=G(2, f 2, g 0) G(0, g 0, h z)=G(2,2,1) G(0,1,2)=8 .
$$

Thus, we have

$$
\mathrm{G}^{2}(\mathrm{fx}, \mathrm{gy}, \mathrm{hz})=4=\frac{1}{2} \cdot 8=\frac{1}{2} \mathrm{G}(\mathrm{x}, \mathrm{fx}, \mathrm{gy}) \mathrm{G}(\mathrm{y}, \mathrm{gy}, \mathrm{hz}) .
$$

In all above cases, inequality (4) of Corollary 2.13 is satisfied for $q=\frac{1}{2}$. Clearly, 2 is the unique common fixed point for all of the three mappings $f, g$ and $h$.

\section{Applications}

Throughout this section, we assume that $X=C([0, T])$ is the set of all continuous functions defined on $[0, T]$. Define $G: X \times X \times X \rightarrow \mathbb{R}^{+}$by

$$
G(x, y, z)=\sup _{t \in[0, T]}|x(t)-y(t)|+\sup _{t \in[0, T]}|y(t)-z(t)|+\sup _{t \in[0, T]}|z(t)-x(t)| .
$$

Then $(X, G)$ is a $G$-complete metric space. Consider the integral equations:

$$
\begin{aligned}
& x(t)=p(t)+\int_{0}^{T} K_{1}(t, s, x(s)) d s, t \in[0, T], \\
& y(t)=p(t)+\int_{0}^{T} K_{2}(t, s, y(s)) d s, t \in[0, T], \\
& z(t)=p(t)+\int_{0}^{T} K_{3}(t, s, z(s)) d s, t \in[0, T],
\end{aligned}
$$

where $\mathrm{T}>0, \mathrm{~K}_{1}, \mathrm{~K}_{2}, \mathrm{~K}_{3}:[0, \mathrm{~T}] \times[0, \mathrm{~T}] \times \mathbb{R} \rightarrow \mathbb{R}$.

The aim of this section is to give an existence theorem for a solution of the above integral equations by using the obtained result given by Corollary 2.5 .

Theorem 3.1. Suppose the following hypotheses hold: 
(i) $\mathrm{K}_{1}, \mathrm{~K}_{2}, \mathrm{~K}_{3}:[0, \mathrm{~T}] \times[0, \mathrm{~T}] \times \mathbb{R} \rightarrow \mathbb{R}$ are all continuous;

(ii) there exists a continuous function $\mathrm{H}:[0, \mathrm{~T}] \times[0, \mathrm{~T}] \rightarrow \mathbb{R}^{+}$such that

$$
\left|K_{i}(t, s, u)-K_{j}(t, s, v)\right| \leqslant H(t, s)|u-v|, i, j=1,2,3
$$

for each comparable $\mathrm{u}, \boldsymbol{v} \in \mathbb{R}$ and each $\mathrm{t}, \mathrm{s} \in[0, \mathrm{~T}]$;

(iii) $\sup _{\mathrm{t} \in[0, \mathrm{~T}]} \int_{0}^{\mathrm{T}} \mathrm{H}(\mathrm{t}, \mathrm{s}) \mathrm{ds} \leqslant \mathrm{q}$ for some $\mathrm{q}<1$.

Then the integral equations (3.2) have a unique common solution $u \in C([0, T])$.

Proof. Define $f, g, h: C([0, T]) \rightarrow C([0, T])$ by

$$
\begin{aligned}
& f x(t)=p(t)+\int_{0}^{T} K_{1}(t, s, x(s)) d s, t \in[0, T], \\
& g y(t)=p(t)+\int_{0}^{T} K_{2}(t, s, y(s)) d s, t \in[0, T], \\
& h z(t)=p(t)+\int_{0}^{T} K_{3}(t, s, z(s)) d s, t \in[0, T] .
\end{aligned}
$$

For all $x, y, z \in C([0, T])$, from (3.1), (3.3), (3.4), and the condition (iii), we have

$$
\begin{aligned}
G(f x, g y, h z)= & \sup _{t \in[0, T]}|f x(t)-g y(t)|+\sup _{t \in[0, T]}|g y(t)-h z(t)|+\sup _{t \in[0, T]}|h z(t)-f x(t)| \\
\leqslant & \sup _{t \in[0, T]}\left|\int_{0}^{T}\left(K_{1}(t, s, x(s))-K_{2}(t, s, y(s))\right) d s\right| \\
& +\sup _{t \in[0, T]}\left|\int_{0}^{T}\left(K_{2}(t, s, y(s))-K_{3}(t, s, z(s))\right) d s\right|+\sup _{t \in[0, T]}\left|\int_{0}^{T}\left(K_{3}(t, s, z(s))-K_{1}(t, s, x(s))\right) d s\right| \\
\leqslant & \sup _{t \in[0, T]} \int_{0}^{T}\left|K_{1}(t, s, x(s))-K_{2}(t, s, y(s))\right| d s \\
& +\sup _{t \in[0, T]} \int_{0}^{T}\left|K_{2}(t, s, y(s))-K_{3}(t, s, z(s))\right| d s+\sup _{t \in[0, T]} \int_{0}^{T}\left|K_{3}(t, s, z(s))-K_{1}(t, s, x(s))\right| d s \\
\leqslant & \sup _{t \in[0, T]} \int_{0}^{T} H(t, s)|x(s)-y(s)| d s+\sup _{t \in[0, T]} \int_{0}^{T} H(t, s)|y(s)-z(s)| d s \\
& +\sup _{t \in[0, T]} \int_{0}^{T} H(t, s)|z(s)-x(s)| d s \\
\leqslant & \left(\sup _{t \in[0, T]} \int_{0}^{T} H(t, s) d s\right)\left(\sup _{t \in[0, T]}|x(t)-y(t)|\right) \\
& +\left(\sup _{t \in[0, T]} \int_{0}^{T} H(t, s) d s\right)\left(\sup _{t \in[0, T]}|y(t)-z(t)|\right)+\left(\sup _{t \in[0, T]} \int_{0}^{T} H(t, s) d s\right)\left(\sup _{t \in[0, T]}|z(t)-x(t)|\right) \\
\leqslant & \left(\sup _{t \in[0, T]} \int_{0}^{T} H(t, s) d s\right)\left(\sup _{t \in[0, T]}\left|x(t)-y(t) H+\sup _{t \in[0, T]}\right| y(t)-z(t) H+\sup _{t \in[0, T]}|z(t)-x(t)|\right) \\
\leqslant & q G(x, y, z) .
\end{aligned}
$$

This proves that the operators $f, g, h$ satisfy the contractive condition (1) appearing in Corollary 2.5 , and hence $f, g$, $h$ have a unique common fixed point $u \in C([0, T])$, that is, $u$ is a unique common solution to the integral equations (3.2).

Corollary 3.2. Suppose the following hypotheses hold: 
(i) $\mathrm{K}:[0, \mathrm{~T}] \times[0, \mathrm{~T}] \times \mathbb{R} \rightarrow \mathbb{R}$ is continuous;

(ii) there exists a continuous function $\mathrm{H}:[0, \mathrm{~T}] \times[0, \mathrm{~T}] \rightarrow \mathbb{R}^{+}$such that

$$
|K(t, s, u)-K(t, s, v)| \leqslant H(t, s)|u-v|
$$

for each comparable $\mathrm{u}, v \in \mathbb{R}$ and each $\mathrm{t}, \mathrm{s} \in[0, \mathrm{~T}]$;

(iii) $\sup _{\mathrm{t} \in[0, \mathrm{~T}]} \int_{0}^{\mathrm{T}} \mathrm{H}(\mathrm{t}, \mathrm{s}) \mathrm{ds} \leqslant \mathrm{q}$ for some $\mathrm{q}<1$.

Then the integral equation

$$
x(t)=p(t)+\int_{0}^{T} K(t, s, x(s)) d s, t \in[0, T]
$$

has a unique common solution $\mathrm{u} \in \mathrm{C}([0, \mathrm{~T}])$.

Proof. Taking $\mathrm{K}_{1}=\mathrm{K}_{2}=\mathrm{K}_{3}=\mathrm{K}$ in Theorem 3.1, then the conclusion of Corollary 3.2 can be obtained from Theorem 3.1 immediately.

\section{Acknowledgment}

This work is supported by the National Natural Science Foundation of China (11071169, 11271105), the Natural Science Foundation of Zhejiang Province (Y6110287).

\section{References}

[1] M. Abbas, T. Nazir, S. Radenović, Some periodic point results in generalized metric spaces, Appl. Math. Comput., 217 (2010), 4094-4099. 1

[2] M. Abbas, B. E. Rhoades, Common fixed point results for noncommuting mappings without continuity in generalized metric spaces, Appl. Math. Comput., 215 (2009), 262-269. 1

[3] H. Aydi, W. Shatanawi, C. Vetro, On generalized weakly G-contraction mapping in G-metric spaces, Comput. Math. Appl., 62 (2011), 4222-4229.

[4] F. Gu, W. Gao, W. Tian, Fixed point theorem and the iterative convergence of nonlinear operator, Harbin Science and Technology Press, Harbin, China, (2002). 1

[5] F. Gu, Z.-Z. Yang, Some new common fixed point results for three pairs of mappings in generalized metric spaces, Fixed Point Theory Appl., 2013 (2013), 21 pages.

[6] F. Gu, Y. Yin, Common fixed point for three pairs of self-maps satisfying common (E.A) property in generalized metric spaces, Abstr. Appl. Anal., 2013 (2013), 11 pages.

[7] F. Gu, D. Zhang, The common fixed point theorems for six self-mappings with twice power type $\Phi$-contraction condition, Thai J. Math., 10 (2012), 587-603. 1

[8] M. Jleli, B. Samet, Remarks on G-metric spaces and fixed point theorems, Fixed Point Theory Appl., 2012 (2012), 7 pages. 1

[9] E. Karapinar, R. P. Agarwal, Further fixed point results on G-metric spaces, Fixed Point Theory Appl., 2013 (2013), 14 pages. 1

[10] Z. Mustafa, H. Aydi, E. Karapınar, On common fixed points in G-metric spaces using (E.A) property, Comput. Math. Appl., 64 (2012), 1944-1956.

[11] Z. Mustafa, H. Obiedat, H. Awawdeh, Some fixed point theorem for mapping on complete G-metric spaces, Fixed Point Theory Appl., 2008 (2008), 12 pages. 1

[12] Z. Mustafa, B. Sims, A new approach to generalized metric spaces, J. Nonlinear Convex Anal., 7 (2006), 289-297. 1, $1.1,1.2,1.3,1.4,1.5,1.6,1.7,1.8,1.9,1.10$

[13] B. Samet, C. Vetro, F. Vetro, Remarks on G-metric spaces, Int. J. Anal., 2013 (2013), 6 pages. 1

[14] W. Shatanawi, Fixed point theory for contractive mappings satisfying $\Phi$-maps in G-metric spaces, Fixed Point Theory Appl., 2010 (2010), 9 pages.

[15] N. Tahat, H. Aydi, E. Karapınar, W. Shatanawi, Common fixed points for single-valued and multi-valued maps satisfying a generalized contraction in G-metric spaces, Fixed Point Theory Appl., 2012 (2012), 9 pages.

[16] H.-Q. Ye, F. Gu, A new common fixed point theorem for a class of four power type contraction mappings, J. Hangzhou Univ. Natur. Sci. Ed., 10 (2011), 520-523.

[17] H.-Q. Ye, F. Gu, Common fixed point theorems for a class of twice power type contraction maps in G-metric spaces, Abstr. Appl. Anal., 2012 (2012), 19 pages. 1 